\title{
STRATEGI PENGEMBANGAN SANGGAR BELAJAR PROGRESIF GUNA PENINGKATAN KUALITAS MANAJEMEN DAN AKADEMIK DI DESA AMBULU KABUPATEN PROBOLINGGO
}

\section{Darwin Djeni*}

\begin{abstract}
The purpose of this research is to know the strategic position of Progressive Learning Studio in Ambulu Village Probolinggo Regency and to determine strategy to improve management and akdemik to survive and develop from quantity and quality aspect. This research was conducted purposively in Sumberasih sub-district of Probolinggo. Analysis conducted by research method Diagram of SWOT analysis, External Factor Analysis Summary (EFAS) and Internal Factor Analysis Summary (IFAS). The results of the study are based on the results of the analysis on the SWOT diagram, from the total value of each factor can be explained that the most appropriate strategy is to compete in the guidance institution in the Sumberasih sub-district by way of improving the facilities and marketing progressive learning studio. The facilities in question are in terms of place and service optimal guidance process and a comfortable place. This is intended to be a different value from existing learning guidance, which is generally the institution stood in urban areas with a relatively high cost. Finally, the progressive learning studio has the opportunity and the power to develop in rural areas. Keywords: SWOT Analysis, Progressive Learning Studio, Quality Management, Academic
\end{abstract}

Keywords: strategic position, Progressive Learning Ambulu improve, management

\section{A. Pendahuluan}

Kondisi pendidikan di Indonesia saat ini selalu berubah sesuai kebijakan Kementrian Pendidikan dan Kebudayaan. Dalam periode ini, sekitar 3 kali kebijakan terkait kurikulum dan jam sekolah diputuskan. Meski begitu, peserta didik tetap mempunyai kewajiban mencapai ketuntasan belajar pada semua bidang pelajaran. Permasalahan yang sering terjadi adalah tidak semua peserta didik mencapai capaian belajar tersebut hanya dengan kegiatan pembelajaran di sekolah. Lembaga Bimbingan Belajar merupakan salah satu lembaga pendampingan belajar yang membantu kesulitan belajar peserta didik untuk lebih memahami materi yang diajarkan di sekolah. Perubahan-perubahan pola pendidikan yang begitu cepat, silih berganti serta globalisasi di segala bidang termasuk bidang pendidikan, memunculkan persaingan yang sangat ketat di bidang bisnis jasa pendidikan. Lembaga non formal seperti bimbingan belajar

\footnotetext{
•darwindjeni15@gmail.com
} 
harus selalu siap dengan perubahan-perubahan yang dikeluarkan pemerintah di bidang pendidikan, juga harus siap bersaing tidak hanya bimbingan belajar sejenis, tetapi sekolah yang menyelenggarakan bimbingan belajar juga merupakan saingan.

Dalam meningkatkan kualitas pendidikan nasional, Lembaga bimbingan Progresif memiliki visi dan misi. Visi lembaga pendidikan Progresif yaitu menjadi institusi pendidikan luar sekolah yang terkemuka, terunggul dan terbesar di Indonesia khusunya di daerah pedesaan. Sedangkan Misi lembaga pendidikan Progresif adalah:

1. Menjadi lembaga bimbingan belajar berskala nasional yang terdepan dalam prestasi.

2. Menjadi tempat karyawan untuk membangun kesejahteraan bersama dan bersama-sama membangun kesejahteraan (Memenuhi kepentingan profesional).

3. Menjadi lembaga bimbingan belajar yang ekonomis dan terjangkau di area pedesaan.

4. Menjadi tempat setiap insan untuk berprestasi, berkreasi dan mengembangkan diri.

5. Menjadi aset pendidikan nasional dan kebanggaan masyarakat khusunya di daerah pedesaan.

Dengan melihat kondisi saat ini, ada beberapa lembaga bimbingan belajar di daerah Probolinggo dari yang memiliki Brand maupun lembaga bimbingan belajar lokal. Namun biasanya lembaga bimbingan belajar terpusat di kota atau sekitar kota yang mana terjangkau dari sekolah baik SD, SMP maupun SMA. Selain itu, biaya lembaga bimbingan tersebut rata-rata mahal dan kurang terjangkau bagi masyarakat desa. Disisi lain, banyaknya pelajar yang berdomisili area Kecamatan Sumberasih khususnya Desa Ambulu yang minim ikut pendampingan belajar dikarenakan faktor ekonomi dan jarak yang kurang terjangkau dari Lembaga Bimbingan yang terpusat di Kota Probolinggo. Lembaga Bimbingan Belajar Progresif di Desa Ambulu Kabupaten Probolinggo berdiri untuk memfalitasi dan meningkatkan kemampuan pelajar tersebut. Target mencapai jumlah siswa yang ideal, fasilitas sarana dan prasarana serta produk yang lebih baik sehingga dapat mensejajarkan diri dengan Lembaga Bimbingan Belajar yang sudah ada terlebih yang memiliki Brand. Dengan kata lain untuk mencapai itu, target Sanggar Belajar Progresif adalah memperoleh jumlah siswa yang lebih banyak. Adapun untuk mencapai jumlah siswa tersebut akan di capai secara bertahap yakni 50 siswa kemudian 75 siswa dan 100 siswa. Oleh karena itu, diperlukan suatu starategi pengembangan lembaga yang lebih baik.

Berdasarkan data di atas dan persaingan yang semakin ketat, maka masalah yang muncul adalah menurunnya jumlah siswa yang ikut bimbingan belajar di sanggar belajar Progresif di Desa Ambulu Kabupaten Probolinggo. Pertanyaan penelitian yang dapat dikembangkan adalah Apa rencana strategis yang dilakukan 
Sanggar Belajar Progresif dalam bidang strategi produk jasa, harga dan promosi untuk dapat meningkatkan jumlah siswa dan bagaimana hasil evaluasi serta rekomendasi kebijakan selanjutnya?

\section{B. Metode Penelitian}

Secara spesifik, sesuai dengan tujuan penelitian akan digunakan beberapa alat analisis baik melalui metode kuantitatif yang diharapkan mampu menjawab permasalahan dan tujuan yang akan dicapai. Proses penyusunan perencanaan strategis melalui tiga tahap analisis yaitu:

1. Tahap pengumpulan data (evaluasi faktor eksternal dan internal)

2. Tahap analisis (Matriks SWOT, Matriks Internal dan Eksternal)

3. Tahap pengambilan keputusan

Tahap pengumpulan data adalah tahap yang pada dasarnya tidak hanya sekedar kegiatan pengumpulan data tetapi juga merupakan suatu kegiatan pengklasifikasian dan pra analisis dimana tahap ini data dibagi menjadi dua bagian yaitu data internal dan data eksternal.

Tahap analisis adalah setelah mngumpulkan semua informasi yang berpengaruh terhadap kelangsungan perusahaan, tahap selanjutnya adalah memanfaatkan semua informasi tersebut dalam model-model kuantitatif perumusan Strategi Bisnis Perusahaan (SBU), Matrik TOWS atau Matrik SWOT dan Matrik Internal Eksternal kemudian dari hasil yang ada maka ditentukan keputusan yang tepat.

Dilihat dari jenis perusahaan, ada strategi perusahaan konglomerasi yang memiliki beberapa Strategic Bussenis Unit (SBU), dan strategi perusahaan kecil dan hanya memiliki satu SBU. Sedangkan dilihat dari tingkatan tugas, strategi dapat diklasifikasikan menjadi strategi geneik (geneic strategy), strategi utama/induk (grand strategy) dan strategi fungsional.

1. Strategi generik

Menurut Porter (2001:32) strategi generic adalah suatu pendekatan strategi peusahaan dalam rangka mengungguli pesaing dalam lembaga bimbingan belajar sejenis. Kemudian Wheelen dan Hunger (2002:33) membagi strategi generic ini menjadi 3 macam yaitu :

a. Strategi stabilitas (stability)

Pada prinsipnya, strategi ini menekankan pada tidak bertambahnya produk, pasar, dan fungsi-fungsi perusahaan lain, karena perusahaan berusaha untuk meningkatkan efisiensi bidang dalam rangka meningkatkan kinerja dan keuntungan.

b. Strategi Ekspansi (expansion)

Pada prinsipnya, strategi ini menekankan pada penambahan atau perluasan produk, pasar, dan fungsi-fungsinya peusahaannya, sehingga aktivitas perusahaan meningkat

c. Trategi Penciutan 
Pada prinsipnya, strategi ini dimaksudkan untuk melakukan pengurangan atas produk yang dihasilkan atau pengurangan atas pasar maupun fungsi-fungsi dalam perusahaan, khususnya yang chasflow negative.

\section{Strategi utama}

Strategi utama merupakan strategi yang lebih operasional dan merupakan tindak lanjut dan strategi generik.

\section{Strategi fungsional}

Strategi fungsional merupakan turunan strategi utama dan lebih bersifat spesifik serta terperinci tentang pengelolaan bidang fungsional tertentu, seperti bidang pemasaran, bidang keuangan, bidang SDM, bidang pelayanan dan lain sebagainya.

Menurut Rangkuty (2009:23) analisis data yang digunakan untuk memecahkan masalah adalah sebagai berikut :

a. Dalam sel Opportunities (O), dirumuskan beberapa peluang yang dihadapi oleh perusahaan. Hal ini harus mempertimbangkan deregulasi lembaga bimbingan belajar sebagai salah satu faktor strategis.

b. Dalam sel Threats (T), menentukan beberapa ancaman yang dihadapi perusahaan.

c. Dalam sel Weaknesses (W), menenukan beberapa kelemahan yang masih membelit perusahaan.

Merumuskan bebeapa kemungkinan alternatife strategi perusahaan berdasarkan pertimbangan kombinasi empat peluang faktor strategi tesebut, yang terdiri dari :

a. Strategi SO, Strategi ini dibuat berdasarkan suatu jalan pikiran, yaitu bagaimana perusahaan menggunakan seluruh kekuatan untuk memanfaatkan peluang.

b. Strategi ST, Strategi ini untuk menggunakan kekuatan yang dimiliki perusahaan dengan cara menghindari ancaman.

c. Strategi WO, Strategi ini diterapkan dengan memanfaat peluang yang ada dan mengatasi kelemahan-kelemahan yang dimiliki.

d. Strategi WT, Strategi ini didasarkan pada kegiatan yang bersifat defensif dan ditujukan meminimalkan kelemahan yang ada serta menghindari ancaman.

Selanjutnya dengan menggunakan faktor strategis baik internal maupun eksternal sebagaimana telah dijelaskan dalam tabel EFAS dan IFAS, lalu melanjutkan tahap satu sampai dengan enam diatas. Transfer peluang dan ancaman (dari tahap ketiga dan keempat). Berdasarkan pendekatan tersebut, dapat dibuat berbagai kemungkinan alternative stratgi (SO, ST, WO, WT).

Sebuah penelitian yang menunjukan bahwa kinerja penjualan perusahaan hasil strategi pemasaran perusahaan dapat ditentukan oleh kombinasi faktor 
internal dan eksternal. Kedua faktor tersebut harus dipertimbangkan dalam analisis SWOT. Analisis SWOT membandingkan antara faktor internal dan eksternal

Tabel 1. Analisis SWOT

\begin{tabular}{|l|l|l|l|}
\hline $\begin{array}{c}\text { Faktor-Faktor } \\
\text { Strategi Internal }\end{array}$ & Bobot & Rating & Nilai \\
\hline $\begin{array}{l}\text { Internal : } \\
\text { 1. Strenght (S) } \\
\text { 2. Weakness (W) }\end{array}$ & $\mathrm{S} 1(0,0-1,0)$ & $\mathrm{W} 2(1-4)$ & $\mathrm{W} 1 \times 0,0-1,0)$ \\
\hline Total & 1,0 & $\mathrm{~W} 2(1-4)$ & $\mathrm{W} 1 \times \mathrm{W} 2=\mathrm{S} 3$ \\
\hline $\begin{array}{l}\text { Ekstenal : } \\
\text { 1. Opportunity }(\mathrm{O})\end{array}$ & $\mathrm{O} 1(0,0-1,0)$ & $\mathrm{O} 2(1-4)$ & $\mathrm{O} 1 \times \mathrm{O} 2=\mathrm{O} 3$ \\
2. Threats (T) & $\mathrm{T} 1(0,0-1,0)$ & $\mathrm{T} 2(1-4)$ & $\mathrm{T} 1 \times \mathrm{T} 2=\mathrm{T} 3$ \\
\hline Total & 1,0 & & \\
\hline
\end{tabular}

Sumber : Ferdy Rangkuti (2009:23)

Keterangan :

1. Bobot dari internal dan eksternal antara 0,0 sampai dengan 1,0

2. Rating dari internal dan eksternal antara 1 sampai 4

Nilai dari internal dan eksternal adalah hasil perkalian antara bobot dengan rating.

\section{Matriks Internal Factor Evaluation (IFE)}

Menurut Umar (2001:172), langkah penyimpulan dalam mengelola internalmanagement dan internal audit dapat dipakai unuk mnyusun matriks IFE. Alat perumusan strategi ini mnyimpulkan dan mengevaluasi kekuatan dan kelemahan yang besar dalam daerah-daerah fungsional perusahaan, dan juga untuk memberikan suatu basis bagi pengidentifikasian dan evaluasi hubungan diantara daerah-daerah tersebut.

Perlu diketahui pula bahwa intuitive judgement sangat diperlukan dalam menggunakan IFE Matrix ini. Setelah fakor-faktor strategi internal suatu perusahaan diidentifikasi, suatu tabel EFI (evaluasi faktor internal) disusun untuk merumuskan faktor-faktor strategi internal tersebut dalam kerangka strengts and weaknes perusahaan.

Tabel 2 Mariks Internal Factor Evaluation (IFE)

\begin{tabular}{|l|l|l|l|}
\hline Faktor Internal & Bobot (i) & Pringkat (ii) & Total (i*ii) \\
\hline Kekuatan & S1 $(0,0-1,0)$ & S2 $(1-4)$ & S1 x S2 $=$ S3 \\
\hline Klemahan & W1 (0,0-1,0) & W2 (1-4) & W1 x W2 = W3 \\
\hline Total & 1,0 & & \\
\hline
\end{tabular}


IFE matrix dapat dikembangkan dalam lima tahap :

a. Buatlah daftar critical success factor seperti yang diidntifikasikan pada interna audit process antara sepuluh sampai dua puluh faktor internal, termasuk faktor kekuatan dan kelemahannya. Buat secara spesifik.

b. Tentukan bobot dengan skala mulai dari 0,0 (tidak penting) sampai 1,0 (sangat penting). Nilai bobot menunjukan kepentingan relatif dari faktor tersebut untuk menjadi sukses dalam industri perusahaannya. Faktor-faktor yang dipertimbangkan untuk memiliki peran yang paling besar pada prestasi organisasi diberi nilai tertinggi demikian pula sebaliknya. Total seluruh bobot harus sama dengan 1,0. Namun pada prakeknya nilai bobot pada faktor-faktor tersebut memiliki kesamaan dan perbedaan karena terdapat banyak faktor yang harus diperhitungkan dan dipertimbangkan.

c. Beri rating antara 1 sampai 4 bagi masing-masing faktor untuk menunjukan apakah faktor tersebut memiliki kelemahan yang besar yaitu :

Tabel 3. Skoring Masing-masing Faktor Internal

Strenght

Rating

$1 \quad$ Kekuatan kecil

$2 \quad$ Kekuatan sedang

$3 \quad$ Kekuatan tinggi

$4 \quad$ Kekuatan sangat besar

\section{Weakness}

\section{Rating Keterangan}

$1 \quad$ Kelemahan yang sangat berani

$2 \quad$ Kelemahan yang cukup berarti

3 Kelemahan yang kurang berarti

$4 \quad$ Kelemahan yang tidak berarti

Sumber : David (2002:145)

d. Kalikan bobot dan rating dari masing-masing faktor untuk menentukan scorenya. Jumlahkan total skor masing-masing variabel. Nilainya merupakan nilai bagi organisasi tersebut dari sisi IFE matriks. Nilai rata-rata adalah 2,5. Jik nilainya dibawah 2,5 menandakan bahwa secara internal perusahaan lemash, sedangkan nilai 2,5 menu jukan posisi inernal yang kuat. Pembobotan dan pemberian rating pada faktor internal ini dilakukan oleh pihak perusahaan yang paling mengetahui kaondisi perusahaan dengan membandingkan dengan pesaing utama atau rata-rata industri serta dengan mempelajari dokumendokumen yang ada diperusahaan.

\section{Matriks Eksternal Faktor Evaluation (EFE)}

Menurut Umar (2001:164), untuk menganalisis lembaga bimbingan belajar menggunakan Eksternal Factor Evalution (EFE) Matrix menghendaki agar para peneliti strategi melakukan pengumpulan data dan menganilisis hal-hal yang 
menyangkut persoalan ekonomi, social, bdaya, demografi, lingkungan, politik, pemerintah, hokum, teknologi, dan informasi tentang persaingan di pasar industri dimana perusahaan berada, bobot EFI (Evaluasi Faktor Internal) dapat dilihat pada tabel dibawah ini :

Tabel 4. Bobot EFI

$\begin{array}{llll}\text { Faktor Eksternal } & \text { Bobot (i) } & \text { Peringkat (ii) } & \text { Total (i*ii) } \\ \text { Opportunity } & \text { O1 }(0,0-1,0) & \text { O2 }(1-4) & \text { O1 x O2= O3 } \\ \text { Threat } & \text { T1 }(0,0-1,0) & \text { T2 }(1-4) & \text { T1 x T2 = T3 }\end{array}$

Total $\quad 1,0$

Sumber : David (2002 : 207)

Sebagai Bahan masukan dan referensi bagi penelitian lanjutan didalam melakukan pengembangan penelitian, khususnya tentang strategi promotional mix, kaitannya dengan peningkatan penjualan. Terdapat lima tahapan didalam mengembangkan matiks EFE :

a. Buat critical success factor yang mencakup perihal opportunities, dan threats. Buatlah secara spesifik dengan menggunakan teknis statistic seperti presentase, rasio dan perbandingan jika memungkinkan.

b. Tentukan bobot critical success factor tadi dengan skala mulai dari 0,0 (tidak penting). Ukuran bobot dapat ditetapkan dengan beberapa cara, misalnya dengan consensus kelompok. Total seluruh bobot harus sama dengan 1,0. Nilai bobot dihitung berdasarkan rata-rata industrinya. Namun pada prakteknya nilai bobot pada faktor-faktor tersebut memiliki kesamaan dan perbedaan karena terdapat banyak faktor yang harus diperhitungkan dan dipertimbangkan. Beri rating antara 1 sampai 4 bagi masing-masing faktor untuk menunjukkan apakah faktor tersebut memiliki kelemahan yang besar yaitu :

c. Selanjutnya tentang rating. Setiap critical success factor diberi rating antara 1 sampai 4, dimana penjelasannya dalam tabel berikut :

Tabel 5 Skoring masing-masing faktor eksternal

$\begin{array}{clcl} & \text { Oppoetunity } & & \text { Threat } \\ \text { Rating } & \text { Keterangan } & \text { Rating } & \text { Keterangan } \\ 1 & \text { Peluang kecil } & 1 & \text { Ancaman sangat besar } \\ 2 & \text { Peluang sedang } & 2 & \text { Ancaman besar } \\ 3 & \text { Peluang tinggi } & 3 & \text { Ancaman sedang } \\ 4 & \text { Peluang sangat tinggi } & 4 & \text { Ancaman sedikit }\end{array}$

Sumber : David ((2002 : 207) 
4. Kalikan masing-masing nilai bobot dengan nilai ratingnya untuk mendapatkan skor untuk semua critical success factor. Jumlahkan semua score untuk mendapatkan nilai roral score untuk perusahaan. Nilai terbesar total score matriks EE adalah 4,0 dan terendah adalah 1,0. Total score 4,0 mengindikasikan bahwa perusahaan meespons peluang yang ada dengan cara yang luar biasa dan menghindari ancaman dipasar industrinya. Total score sebesar 1,0 menunjukkan strategi-strategi perusahaan tidak memanfaatkan peluang-peluang atau tidak menghindari ancaman eksternal.

\section{Menentukan Posisi Strategi Pemberdayaan UMKM Dengan Diagram SWOT}

Penelitian menunjukkan bahwa tingkat kemajuan usaha UMKM dapat ditentukan oleh kombinasi faktor internal dan eksternal. Kedua faktor tersebut harus dipertimbangkan dalam analis SWOT. SWOT adalah singkatan dari lingkungan Internal Strengths dan Weakness serta lingkungan eksternal Opportunities dan Threats yang dihadapi dunia bisnis. Analisis SWOT membandingkan antara faktor eksternal peluang (opportunities) dan Ancaman (threats) dengan faktor internal Kekuatan (strengths) dan Kelemahan (weaknesses).

Berikut adalah contoh gambar diagram SWOT :

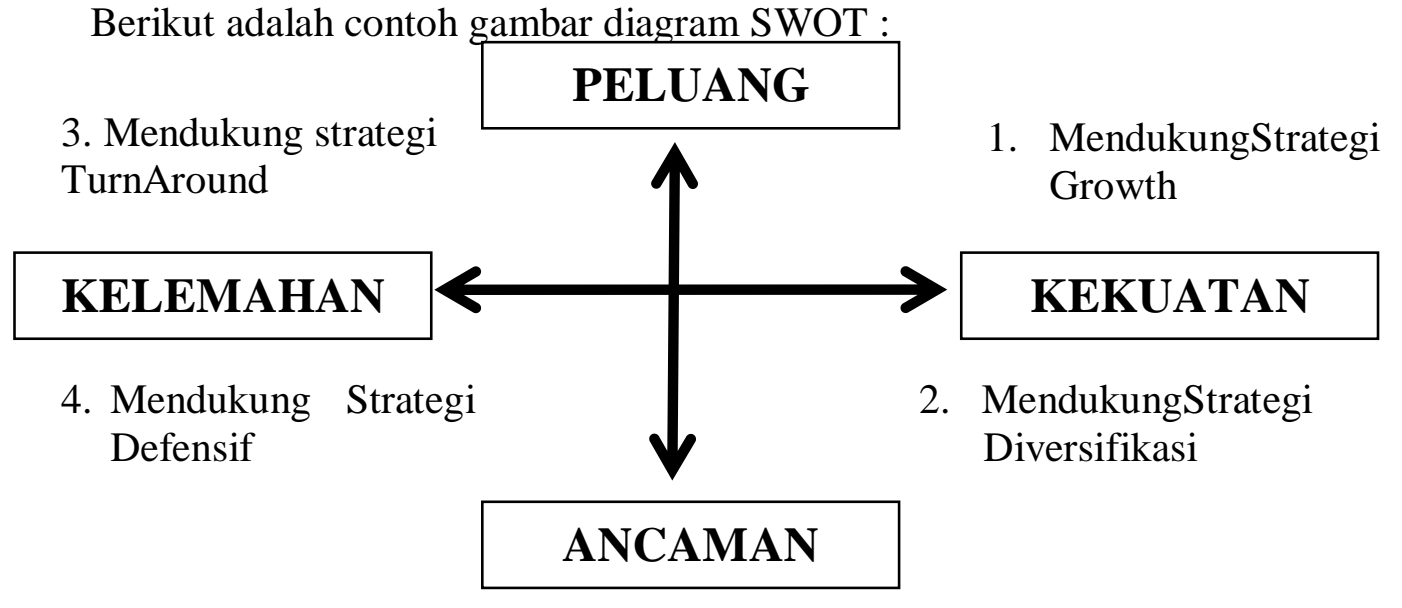

Sumber : Fedy Rangkuti, (2009 : 19)

Gambar 2. Diagram Analisi SWOT

Kuadran 1: Ini Merupakan situasi yang sangat menguntungkan. Perusahaan tersebut memiliki peluang dan kekuatan sehingga dapat memanfaatkan peluang yang ada. Strategi yang harus diterapkan dalam kondisi ini adalah mendukung kebijakan pertumbuhan yang agresif (Gowth oriented strategy).

Kuadran 2: Meskipun menghadapi berbagai ancaman, perusahaan ini masih memiliki kekuatan dari segi internal. Strategi yang harus diterapkan adalah menggunakan kekuatan untuk memanfaatkan peluang jangka panjang dengan cara strategi diversifikasi (produk/jasa). 
Kuadran 3 : Perusahaan menghadapi peluang pasar yang sangat besar, tetapi di lain pihak, perusahaan menghadapi beberapa kendala atau kelemahan internal. Kondisi kuadran 3 inni mirip dengan Question Mark pada BCG matrik. Focus trategi perusahaan ini adalah meminimalkan masalah-masalah internal perushaan sehibgga dapat merebut peluang pasar yang lebih. Misalnya, Apple menggunakan strategi peninjauan kembali teknologi yang dipergunakan dengan cara menawarkan produk-produk baru dalam lembaga bimbingan belajar micro computer.

Kuadran 4: ini merupakan situasi yang tidak menguntungkan, perusahaan tersebut menghadapi bebagai ancaman dan kelemahan internal.

\section{Menentukan Penerapan Strategi Pemberdayaan UMKM Dengan Diagram SWOT}

Setelah mengetahui gambaran strategi usaha melalui IE Matix, maka selanjutnya untuk menentukan strategi pemasaran yang akan diterapkan adalah dengan menggunakan analisa SWOT dalam Matrix SWOT ini akan dihasilkan beberapa alternatif strategi yang merupakan hasil penggabungan faktor-faktor strategi usaha yang telah teridentifikasi sebelumnya. Penggambaran matrik SWOT adalah sebagai berikut.

Merumuskan beberapa kemungkinan alternatif strategi perusahaan berdasarkan pertimbangan kombinasi empat peluang faktor strategi tersebut yang terdiri dari :

a. Strategi SO, Strategi ini dibuat berdasarkan suatu jalan pikiran, yaitu bagaimana perusahaan menggunakan seluruh kekuatan untuk memanfaatkan peluang.

b. Strategi ST, Strategi ini untuk menggunakan kekuatan yang dimiliki perusahaan dengan cara menghindari ancaman.

c. Strategi WO, Strategi ini diterapkan dengan memanfaat peluang yang ada dan mengatasi kelemahan-kelemahan yang dimiliki.

d. Strategi WT, Strategi ini didasarkan pada kegiatan yang bersifat defensif dan ditujukan meminimalkan kelemahan yang ada serta menghindari

Tabel 6. Matrix SWOT

\begin{tabular}{|c|c|c|}
\hline IFAS & STRENGHT (S) & WEAKNESS (W) \\
\hline & $\begin{array}{l}\text { Tentukan faktor kekuatan } \\
\text { internal perusahaan }\end{array}$ & $\begin{array}{l}\text { Tentukan } \\
\text { kelemahan } \\
\text { perusahaan }\end{array}$ \\
\hline OPPORUNITY (O) & STRATEGI (SO) & STRATEGI (WO) \\
\hline $\begin{array}{l}\text { Tentukan faktor } \\
\text { peluang eksternal }\end{array}$ & $\begin{array}{l}\text { Ciptakan } \quad \text { strategi } \\
\text { menggunakan }\end{array}$ & $\begin{array}{l}\text { Ciptakan strategi yang } \\
\text { meminimalkan }\end{array}$ \\
\hline
\end{tabular}


peluang

THREAT (T)

Temukan

ancaman

perusahaan
STRATEGI (ST)

faktor

eksternal

Ciptakan

menggunakan

untuk mengatasi ancaman memanfaatkan peluang

\section{STRATEGI (WT)}

strategi Ciptakan strategi yang

menimalkan kelemahan

dari menghindari

ancaman

Sumber: Rangkuti, 2004 :138

Kekuatan dari gambar matrix SWOT diatas adalah sebagai berikut :

a. Strategi Kekuatan-Peluang (SO)

Strategi yang dihasilkan pada kombinasi ini adalah memanfaatkan kekuatan atas peluang terindifikasi.

b. Strategi Kelemahan-Peluang (WO)

Kesempatan yang dapat teindifikasi tidak mungkin dimanfaatkan karena kelemahan UMKM kerajinan kayu dan kerang di Kecamata Penarukan.

c. Strategi Kekuatan-Ancaman (ST)

Strategi ini mencari kekuatan yang dimiliki oleh UMKM kerajinan kayu dan kerang di Kecamatan Panarukan dapat mengurangi atau menangkal ancaman tersebut.

d. Strategi Kelemahan-Ancaman (WT)

Dalam menghadapi ancaman dan kelemahan internal, strategi yang digunakan adalah keluar dari situasi terjepi.

\section{Hasil Penelitian}

Analisis SWOT digunakan untuk mengidentifikasi dan menganalisis faktorfaktor strategis internal dalm kerangka Strength dan Weakness, serta faktor-faktor strategis eksternal dalam kerangka Oppurtunity dan Threth. Berdasarkan analisa tersebut kemudian akan ditentukan strategi alternatif apakah yang paling tepat untuk meningkatkan usaha dan terus mengembangkannya.

1. Analisis Faktor Internal Menggunakan IFAS

Tahap-tahap dalam menyusun tabel Internal Faktor analysis Summary (IFAS) dengan menggunakan faktor-faktor yang menjadi Strength dan Weakness Langkah selanjutnya yaitu memberikan bobot masing-masing faktor dengan skala mulai dari 0.0 sampai 1.0. Nilai 0.0 yang berarti "tidak penting" sampai dengan 1.0 yang berarti "sangat penting" dimana bobot tersebut jumlahnya tidak melebihi skor total yaitu 1.0.

Menghitung rating untuk masing-masing faktor dengan memberikan skala mulai dari 1 sampai dengan 4. Nilai rating Strength dan Weakness selalu bertolak belakang. Hasil analisis pada tabel Internal Faktor analysis Summary (IFAS) dapat dilihat pada tabel berikut ini.

Tabel 7. Faktor Strategi Internal 
Faktor-faktor Strategi Internal Bobot Rating Nilai Skor

Streangth

1. Lokasi

0.1

3

0.3

2. Sumber Daya Manusia

$0.25 \quad 3$

0.75

3. Potensi Perkembangan

$0.1 \quad 4$

0.4

4. Biaya Bimbingan

0.15

3

0.45

Sub Total

0.600

1.9

Weakness (W)

1. Akses Modal,.

0.1

3

0.3

2. Teknologi

0.05

2

0.1

3. Kemampuan Manajerial

0.15

4

0.6

4. Fasilitas

0.1

3

0.3

Sub Total

0.400

1.3

Dari hasil analisis tabel 7. IFAS faktor Strength mempunyai nilai total 1.9 sedangkan untuk faktor Weakness mempunyai nilai skor 1.3

\section{Analisis Faktor Eksternal Menggunakan EFAS}

Tahap-tahap dalam menyusun tabel Eksternal Faktor analysis Summary (EFAS) dengan menggunakan faktor-faktor yang menjadi Oppurtunity dan Threath Langkah selanjutnya yaitu memberikan bobot masing-masing faktor dengan skala mulai dari 0.0 sampai 1.0. Nilai 0.0 yang berarti "tidak penting" sampai dengan 1.0 yang berarti "sangat penting" dimana bobot tersebut jumlahnya tidak melebihi skor total yaitu 1.0 .

Menghitung rating untuk masing-masing faktor dengan memberikan skala mulai dari 1 sampai dengan 4. Nilai rating Oppurtunity dan Threath selalu bertolak belakang. Hasil analisis pada tabel Eksternal Faktor analysis Summary (EFAS) dapat dilihat pada tabel berikut ini.

Tabel 8. Faktor Strategi Eksternal

Faktor-faktor Strategi Eksternal

Bobot

Rating

Nilai Skor 
Opputunity (O)

1. Pendapatan Masyarakat

$0.05 \quad 3$

0.15

2. Jumlah Siswa

0.15

4

0.6

3. Pendidikan

0.1

3

0.3

4. Antusias Wali Murid

0.15

4

0.6

5. Dukungan Pemerintah

0.05

3

0.15

Sub Total

0.500

2.4

Threath (T)

1. Pesaing.

0.15

4

0.6

2. Harga Fluktuatif

0.1

3

0.3

3. Brand Nama

0.15

3

0.45

4. Kemitraan

0.1

2

0.2

Sub Total

0.500

1.55

Dari hasil analisis tabel 8. EFAS faktor Opputunity mempunyai nilai total 2.4 sedangkan untuk faktor Threath mempunyai nilai skor 1.55

3. Penentuan Posisi Strategis Sanggar Belajar

Analisis Tabel IFAS faktor Strength mempunyai nilai total 1.9 sedangkan untuk faktor Weakness mempunyai nilai skor 1.3 serta tabel EFAS faktor Opputunity mempunyai nilai total 2.4 sedangkan untuk faktor Threath mempunyai nilai skor 1.55 . Selanjutanya dicari nilai selisih skor Strength dan Weakness didapat (+)0.6, sedangkan selisih skor Opputunity dan Treath yaitu (+) 0.85. Berdasarkan hasil identifikasi faktor-faktor tersebut maka dapat digambarkan dalam Diagram SWOT, dapat dilihat pada gambar

Mendukung strategi TurnAround

\section{KELEMAHAN}

PELUANG

(+) 0.85

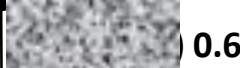

0.6
MendukungStrategi Growth

Mendukung Strategi Defensif 
Dari nilai total masing-masing factor tersebut dapat dijelaskan bahwa strategi yang paling tepat dilakukan untuk meningkatkan jumlah siswa dengan cara mendukung strategi "Growth" baik pada promosi dan pelayan serta fasilitas sanggar belajar progresif. Selain digambarkan dalam diagram analisis SWOT, Juga digambarkan dalam rumusan matrik SWOT, dapat dilihat pada tabel berikut.

Tabel 9 IFAS dan EFAS

\begin{tabular}{|c|c|c|}
\hline IFAS & STRENGHT (S) & WEAKNESS (W) \\
\hline OPPORUNITY & STRATEGI (SO) & STRATEGI (WO) \\
\hline$(\mathrm{O})$ & $\begin{array}{l}\text { Menggunakan kekuatan } \\
\text { untuk memanfaatkan } \\
\text { peluang } \\
=1.9+2.4=4.3\end{array}$ & $\begin{array}{l}\text { Meminimalkan kelemahan } \\
\text { untuk memanfaatkan } \\
\text { peluang } \\
=1.3+2.4=3.7\end{array}$ \\
\hline THREAT (T) & STRATEGI (ST) & STRATEGI (WT) \\
\hline & $\begin{array}{l}\text { Menggunakan kekuatan } \\
\text { untuk mengatasi ancaman } \\
=1.9+1.55=3.45\end{array}$ & $\begin{array}{l}\text { Menimalkan kelemahan } \\
\text { dari menghindari ancaman } \\
=1.3+1.55=2.85\end{array}$ \\
\hline
\end{tabular}

Berdasarkan perhitungan jumlah nilai masing-masing factor diketahui untuk strategi Strength-Opputunity (SO) sebesar 4.3, strategi StrengthThreath (ST) sebesar 3.45, strategi Weakness-Opputunity (WO) sebesar 3.7 serta strategi Weakness-Threath (WT) sebesar 2.85. Nilai tertinggi berada pada Strength-Opputunity yaitu oada kuadran I yaitu dengan melakukan strategi "Growth" usaha pada Sanggar Belajar Progresif di Desa Ambulu Kecamatan Sumberasih.

\section{Matriks SWOT}

Berdasarkan analisis matrik IFAS dan EFAS disusun pula kombinasi strategi matrik SWOT untuk menganalisis rumusan alternative strategi SO, WO, ST, WT dengan hasil analisis pada tabel berikut.

Tabel 10. Matriks SWOT

IFAS STRENGHT (S) WEAKNESS (W)




\begin{tabular}{|c|c|c|}
\hline & $\begin{array}{l}\text { 1. Lokasi } \\
\text { 2. Sumber daya manusia } \\
\text { 3. Potensi perkembangan } \\
\text { 4. Biaya bimbingan }\end{array}$ & $\begin{array}{l}\text { 1. Akses modal } \\
\text { 2. Teknologi } \\
\text { 3. Kemampuan } \\
\text { Manajerial } \\
\text { 4. Fasilitas }\end{array}$ \\
\hline $\begin{array}{l}\text { OPPORUNITY }(\mathrm{O}) \\
\text { 1. Pendapatan } \\
\text { masyarakat } \\
\text { 2. Jumlah siswa } \\
\text { 3. Pendidikan } \\
\text { 4. Antusias wali } \\
\text { murid } \\
\text { 5. Dukungan } \\
\text { pemerintah }\end{array}$ & $\begin{array}{l}\text { STRATEGI (SO) } \\
\text { 1. Meningkatkan Promosi } \\
\text { untuk Pengenalan LBB. } \\
\text { 2. Mempertahankan Harga } \\
\text { Ekonomis yang } \\
\text { Bersaing } \\
\text { 3. Mengembangkan } \\
\text { Fasilitas dan pelayanan } \\
\text { LBB }\end{array}$ & $\begin{array}{l}\text { STRATEGI (WO) } \\
\text { 1. Meningkatkan } \\
\text { pengajuan proposal } \\
\text { kerja sama } \\
\text { 2. Meningkatkan Sistem } \\
\text { Manajerial } \\
\text { 3. Harga Disesuaikan } \\
\text { dengan Pengeluaran } \\
\text { LBB }\end{array}$ \\
\hline $\begin{array}{l}\text { THREAT }(\mathrm{T}) \\
\text { 1. Pesaing. } \\
\text { 2. Harga fluktuatif. } \\
\text { 3. Brand nama, } \\
\text { 4. Kemitraan }\end{array}$ & $\begin{array}{l}\text { STRATEGI (ST) } \\
\text { 1. Membuka Promosi via } \\
\text { online } \\
\text { 2. Meningkatkan SDM } \\
\text { 3. Fokus terhadap } \\
\text { Pelayanan dan Fasilitas }\end{array}$ & $\begin{array}{l}\text { STRATEGI (WT) } \\
\text { 1. Meningkatkan Jumlah } \\
\text { Mitra Kerja Sama } \\
\text { 2. Meningkatkan Referensi } \\
\text { Manajerial yang baik } \\
\text { 3. Fasilitas dikembangkan. }\end{array}$ \\
\hline
\end{tabular}

4. Implementasi Strategi Yang Bisa Diterapkan

Implementasi strategi yang bisa diterapkan di Sanggar Belajar Progresif di Desa Ambulu Kecamatan Sumberasih yang bisa disusun yaitu :

a. Pertumbuhan dilakukan dengan cara meningkatkan fasilitas, kerjasama, pelayanan, manajerial yang baik, pemasaran yang optimal. Semakin Meningkat aspek tersebut maka siswa dan wali murid merasa puas, dengan begitu timbulnya kepercayaan wali murid dan anak lebih kuat. Dampaknya wali murid dan siswa akan mempromosikan kepada rekan, keluarga serta orang lain.

b. Harga yang ditawarkan harus tetap bersaing dan ekonomis mengambil sisi di bawah harga bimbingan yang berada di kota. Hal ini berbanding lurus karena biaya gedung jauh lebih murah dari pada di kota.

c. Pelayanan dan Fasilitas lebih diutamakan yang sangat dibutuhkan siswa, yaitu proses belajar dan media serta fasilitas yang mendukungnya kelancaran dan kenyaman pembelajaran. 
d. Mitra kerja sama diperluas dengan cara menambah mitra di sekitar lokasi LBB khususnya sekolah di area Desa Ambulu. Dengan harapan ada dampak positif LBB berdiri di area Desa Ambulu.

e. Meningkatkan SDM, hal ini agar membantu kondusifnya dan terfokusnya pembelajaran yang berlangsung. Mengadakan SDM yang sesuai dengan bidangnya. Kemudian mengadakan pelatihanpelatihan guna meningkatkan pengalaman dan kreatifitasnya, hal ini dilakukan untuk kesiapan diri Tentor dan Tenaga Kerja lainnya agar bisa membaca situasi peluang dan ancaman. Dengan harapan supaya lebih kreatif dan inovatif.

\section{Kesimpulan}

Berdasarkan hasil analisis pada penelitian ini, maka dapat diambil kesimpulan yang pertama tentang posisi strategis sanggar belajar Progresif berdasarkan hasil analisis SWOT bahwa strategi yang tepat dilakukan adalah strategi "Growth" yaitu dengan melakukan perkembangan dan peningkatan fasilitas dan pelayan serta SDM dan manajerial, sehingga pelayanan dan fasilitas tersebut memiliki banyak alternative dan bisa rasakan atau dinikmati oleh siswa dan wali murid.

Berdasarkan hasil analisis pada matrik SWOT pada perencanaan strategis Sanggar Belajar Progresif di Desa Ambulu Kecamatan Sumberasih kabupaten Probolinggo, maka strateginya adalah :

1. Pertumbuhan dilakukan dengan cara meningkatkan fasilitas, kerjasama, pelayanan, manajerial yang baik, pemasaran yang optimal.

2. Harga yang ditawarkan harus tetap bersaing dan ekonomis mengambil sisi di bawah harga bimbingan yang berada di kota.

3. Pelayanan dan Fasilitas lebih diutamakan yang sangat dibutuhkan siswa.

4. Mitra kerja sama diperluas dengan cara menambah mitra di sekitar lokasi LBB khususnya sekolah di area Desa Ambulu.

5. Meningkatkan SDM, hal ini agar membantu kondusifnya dan terfokusnya pembelajaran yang berlangsung. 


\section{Daftar Pustaka}

Doney, Patricia M and Joseph P Cannon. An Examination Of The Nature Of Trust In Buyer-Seller Relation Ships. Jurnal Of Marketing Vol 61 P 35-51.

Handoko, Tanoto. 2002. Formulasi Strategi Pemasaran Pelumas Repsol pada PT. Sukabumi Trading Coy Jateng. Tesis : Program Magister Manajemen Universitas Diponegoro.

Harper, Orvile C. Walker, Jean Claude Larreche. 2000. Manajemen Pemasaran: Suatu Pendekatan Strategis dengan Orientasi Global. Jakarta: Erlangga.

Jain, C. S. 1990. Marketing Planning and Strategy. $3^{\text {td }}$ edition Boston, South Western Publishing Coy.

Kotler, Philip. 2000. Manajemen Pemasaran Edisi Millenium. Alih Bahasa Hendra Teguh, SE, AKT (ed, Ronny A. Rusli, SE, AKT), Jakarta.

Kusuma, S.T. 1987. Psiko Diagnostik. Yogyakarta : SGPLB Negeri Yogyakarta.

Lupiyoadi, Rambat dan Hamdani, A. 2006. Manajemen Pemasaran Jasa. Edisi 2, Salemba Empat.

Pasuraman A Valerie A Zeithaml, Leonard L Berry. 1988. Seruqual: A Multiple Item Scale Of Measuring Consumer Repceptions Of Service Quality. Jurnal Of Realiting P 12-40.

Pelhan, Afred M. 1997. Mediating Influences On The Relationship Battween Market Orentation and Probility Is Small Industrian Firms. Jurnal Of Marketing.

Robert, B. W. 1997. Customer Value: The Next Source for Competitive Advantage. Journal of Academy of Marketing Science, Vol 25.

Setianto, Agus. 2004. Analisis Efektivitas Orientasi Pasar, Inovasi, Kualitas Layanan dan Kinerja Pemasaran Pengaruhnya terhadap Keunggulan Bersaing. Tesis, Program Magister Manajemen Universitas Diponegoro.

Sidik, Ignas. 2000. Pemasaran Stratejik dan Strategi Pemasaran. Jurnal Forum Manajemen Prasetya Mulya No. 72, Tahun ke 14, p. 14-19.

Sistianto, Drs. 2003. Analisis Pengaruh Orientasi Pasar, Inovasi dan Startegi Pemasaran terhadap Kinerja Pemasaran. Tesis : Program Magister Manajemen Universitas Diponegoro.

Tade Palli, Raghu and Ramon A, Avilla. 1999. Market Orientation and The Marketing Strategy Process. Journal of Marketing Theory and Practice, Spring, p. 69-82. 
Yeny A. Rosemeilia. 2007. Evaluasi Strategi Pemasaran Pada Lembaga Bimbingan Belajar Progresif di Desa Ambulu Kabupaten Probolinggo. Tesis, Program Magister Manajemen Universitas Diponegoro. 